\title{
El arte rupestre de San Juan de Yarucaya, distrito de Cochamarca, Oyón
}

\section{The rock art of San Juan de Yarucaya, district of Cochamarca, Oyón}

\author{
Pieter van Dalen Luna \\ https://orcid.org/000o-0002-2498-9242 \\ Universidad Nacional Mayor de San Marcos \\ pvandalenl@unmsm.edu.pe
}

\section{RESUMEN}

La sierra de Lima presenta una gran variedad de sitios arqueológicos con quilcas o pinturas rupestres, los cuales corresponden a diferentes periodos cronológicos prehispánicos. En el presente estudio presentamos el registro de tres sitios con pinturas ubicados en la Comunidad Campesina de Yarucaya, distrito de Oyón; constituyéndose en una de las primeras referencias sobre el arte rupestre de esta provincia, tan cerca de Lima, pero tan olvidada por la arqueología.

Palabras clave: Quilcas; arte rupestre; provincia de Oyón; cuenca alta del río Huaura; pinturas rupestres.

\section{ABSTRACT}

The Sierra of Lima presents a great variety of archaeological sites with quilcas or cave paintings, which correspond to different pre-Hispanic chronological periods. In the present study we present the registry of three sites with paintings located in the Campesino Community of Yarucaya, Oyón district; constituting one of the first references on rock art in this province, so close to Lima, but so forgotten by archeology. 
Keywords: Quilcas; cave art; Oyón province; upper basin of the Huaura river; cave paintings.

RECIBIDO: 02/09/2020 - ACEPTADO: 14/05/2021 - PubLICADO: 25/06/2021

\section{INTRODUCCIÓN}

Desde el año 2017 hasta el 2019, el autor del presente artículo ha dirigido trabajos de investigación arqueológica de carácter prospectivo en todo el ámbito del distrito de Cochamarca, provincia de Oyón, región Lima Provincias. Como resultado de estas investigaciones se registraron 107 sitios arqueológicos de diferentes periodos culturales, de los cuales Yarucaya tiene 51 sitios arqueológicos, 8 de ellos son sitios conformados por pinturas rupestres.

En esta oportunidad presentamos los 3 sitios más extensos con quilcas, que hemos registrado, como son los de Shansha, Intirumi y Pintimachay. Estos sitios forman parte de una extensa tradición rupestre que se desarrolló en la cuenca alta del río Huaura en periodo Precerámico, extendiéndose en el tiempo hasta periodos prehispánicos tardíos.

La Comunidad y pueblo de Yarucaya es pequeña, pero de fundación española, constituyéndose desde la Colonia en anexo de la doctrina de Cochamarca, pasando a formar su anexo con la creación distrital. En periodos prehispánicos tardíos este territorio formó parte de la nación Andax que se desarrolló en gran parte de la margen derecha de la cuenca alta del río Huaura, la cual fue dominada por los Incas y sometida al Tawantinsuyu.

El río Yarucaya es uno de los principales afluentes del río Huaura, que se une a este por la margen derecha, con más de 50 kilómetros de longitud. Entre sus afluentes principales está el río Shihuincocha con $25 \mathrm{Kms}$ de longitud por la margen derecha. En su recorrido va recibiendo a numerosas quebradas como: Chalhuapuquio, Shulush, Laguna Seca, Jucha Rumi, Chunchumachay, Chinchihuari, Cantioc, Yanapince, Culacorral, Cachintama, Queshupata, entre otras pequeñas por la margen derecha; mientras que por la margen izquierda recibe las aguas de las quebradas tributarias de: Churacocha y Luis Puquio. En su margen derecha se encuentra el pueblo de Cochamarca, capital del distrito del mismo nombre. Este río también se conoce con el nombre de río Cochamarca. Se une al río Huaura, cerca de la localidad de Sayán. La cuenca del río Yarucaya discurre por el territorio de las comunidades de Maní, Yarucaya y Cochamarca; presentando un territorio muy accidentado, con elevados cerros abruptos que se elevan desde el mismo cauce del río

\section{SITIO ARQUEOLÓGICO DE SHANSHA}

Se encuentra localizado sobre una altipampa de ligera inclinación, con abundantes afloramientos rocosos (una especie de bosque de piedras), denominado Shansha, en 
la margen derecha de la sub cuenca del río Yarucaya, en los territorios de la Comunidad Campesina de San Juan de Yarucaya, distrito de Cochamarca, provincia Oyón, región Lima. El acceso al sitio se realiza, desde el pueblo de San Juan de Yarucaya, siguiendo un camino de herradura con dirección al oeste, se arriba a la zona de Illa Punta y luego se desvía por un pequeño camino llegando a Shansha (ver figura 01).

El sitio está conformado por abrigos rocosos que se detallan a continuación:

Abrigo rocoso $\mathrm{N}^{\circ}$ 01: Se ubica al lado norte del sitio, debajo de una peña de coloración rojiza, en las coordenadas UTM: 18L, 269074E, $8801200 \mathrm{~N}$, a una altitud de $3957 \mathrm{~m} \mathrm{~s}$. n. m. Se trata de un abrigo rocoso que está orientado de oeste a este, con 5 metros de ancho por $1.50 \mathrm{~m}$ de profundidad y una altura de 2.50 metros. En el interior del abrigo se aprecia una estructura funeraria (chulpa) de planta rectangular, de 0.95 metros de alto, 3.20 metros de largo (en el eje del ancho del abrigo) y 0.80 metros de ancho (en el eje de la profundidad del abrigo); edificado con piedras canteadas medianas unidas con argamasa (muy destruido), la cual está adosada a la roca. En el interior de la chulpa se observa en superficie regular cantidad de osamenta humana desarticulada y fragmentada entre: cráneo, fémur; los cuales están cubiertos con piedras y estiércol de animal vacuno.

Al ingresar, en la parte derecha de la chulpa y por encima de esta, sobre una superficie plana de la pared rocosa, a una altura de un metro desde la superficie, existe una pintura rupestre en color rojo ocre, consiste de dos figuras; la primera corresponde a un motivo antropomorfo que se encuentra de pie (la figura no se identifica bien), de la segunda figura solo se puede apreciar una mancha roja no se puede identificar su silueta ya que se encuentra alterada por diversos factores ambientales (ver figuras 02, 03, 04, 05 y 06)

Abrigo rocoso $\mathrm{N}^{\circ}$ 02: Se localiza al lado sureste del abrigo rocoso $\mathrm{N}^{\circ}$ 01, en las coordenadas UTM: 269102E, $8801148 \mathrm{~N}$, a una altitud de $3847 \mathrm{~m} \mathrm{~s}$. n. m. Se trata de un abrigo rocoso que está orientado de oeste a este, con 6 metros de ancho, $2 \mathrm{~m}$ de profundidad y una altura de 4 metros. En el interior se encuentra una pequeña sección de basamento de muro, que conformaba una especie de gradería con fines ceremoniales (altar), denominado por los pobladores de la zona como "patacha", la cual se encuentra en el lado izquierdo del abrigo, adosado a la roca. En la parte plana de la pared rocosa se ha evidenciado pinturas rupestres de color rojo ocre, a manera de manchas dispersas en toda la roca, la cual no se ha podido definir la forma debido al deterioro que presenta (ver figuras 07, 08, 09, 10 y 11).

Abrigo rocoso $\mathrm{N}^{\circ}$ 03: Se encuentra ubicado al lado sur del abrigo rocoso $\mathrm{N}^{\circ} 1$, debajo de una roca de gran tamaño, en las coordenadas UTM: 269030E, 8800859N, a una altitud de $3802 \mathrm{~m} \mathrm{~s}$. n. m. Se trata de un abrigo rocoso que se encuentra orientado de este a oeste, con un ancho de 3 metros de ancho, 2.50 metros de altura y una profundidad de 1 metro. En la parte plana de la roca se aprecia la existencia de pin- 

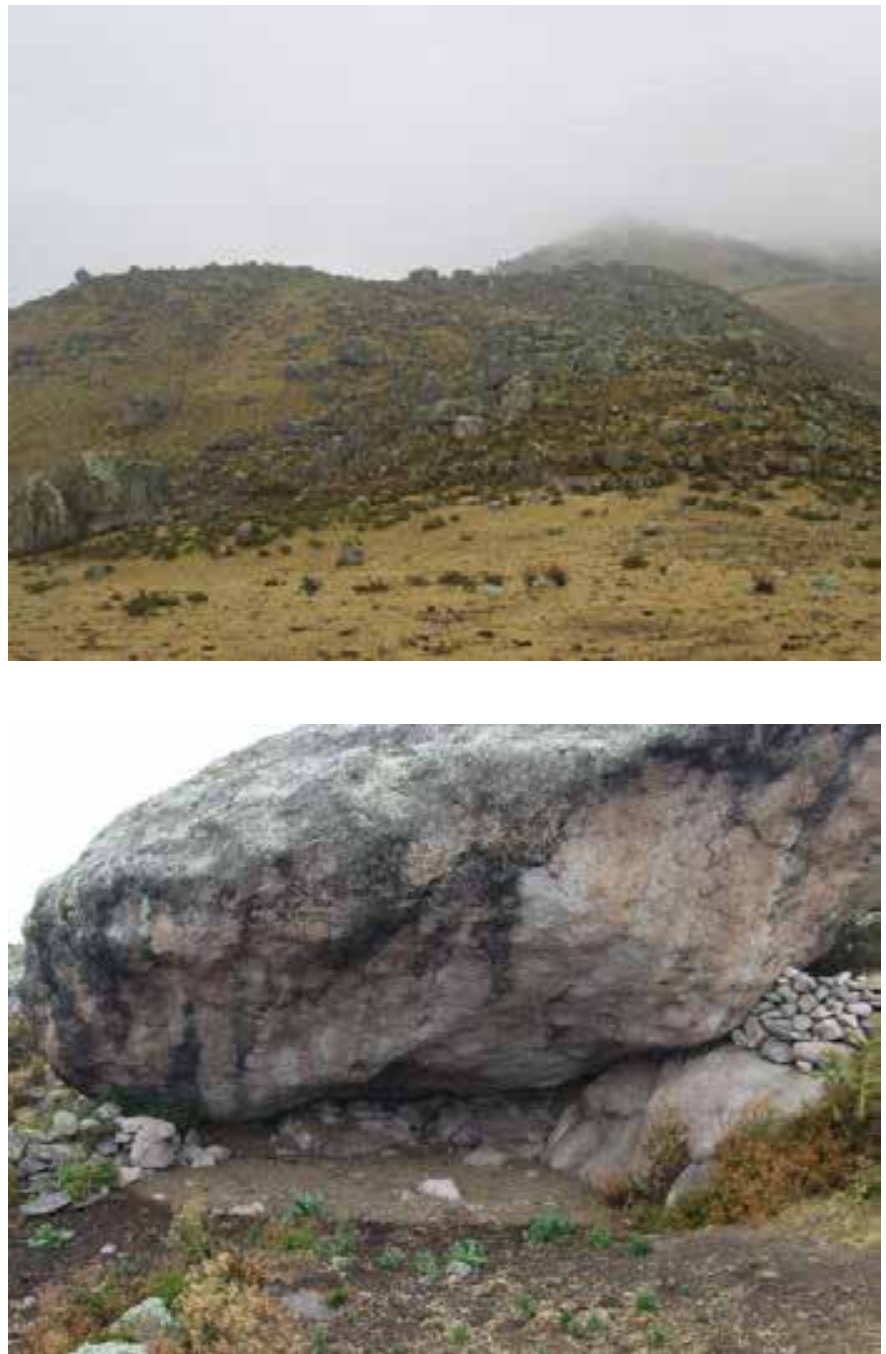

Figura 01. Vista Panorámica del sitio arqueológico de Shansha, foto tomada desde el lado sur del sitio.

Figura 02. Vista Panorámica del Abrigo Rocoso $N^{\circ} 1$ de Shansha, en cuyo interior hay una estructura funeraria y pintura rupestre, foto tomada desde el lado este.
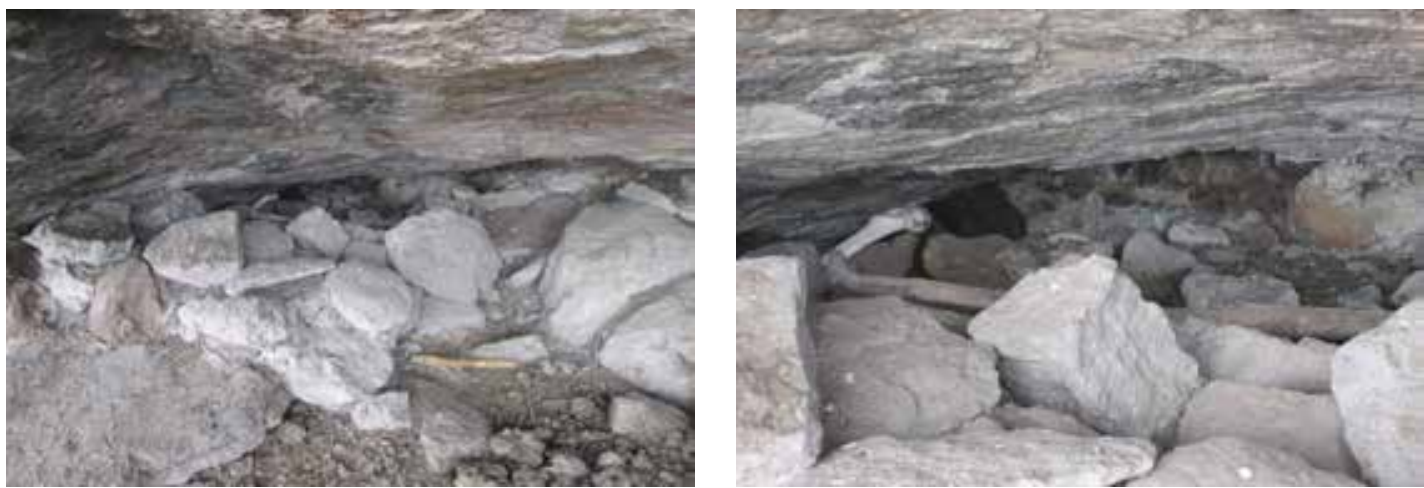

Figura 03 (izquierda). Vista de detalle del interior de dicha estructura donde se aprecian restos óseos humanos. Figura 04 (derecha): vista en detalle de la estructura funeraria de planta rectangular correspondiente al abrigo rocoso 1 del sitio de Shansha. 

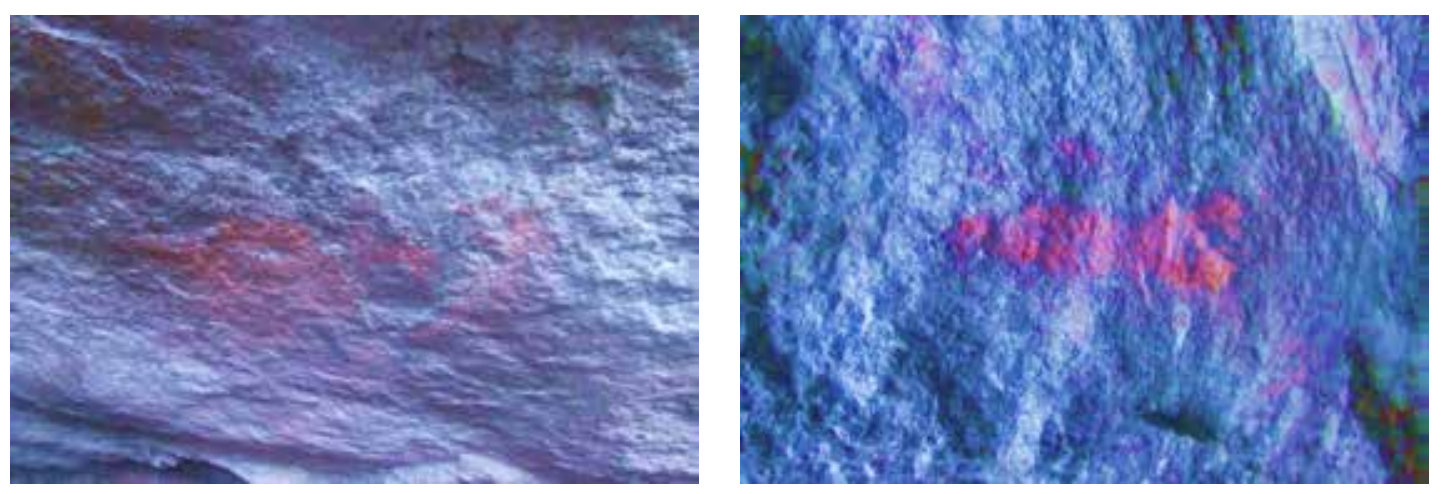

Figura 05 (izquierda). Vista en detalle de una mancha de color rojo ubicada en el interior del abrigo rocoso 1 (motivo 1). Figura 6 (derecha). Vista en detalle de un motivo antropomorfo asociado a la estructura funeraria, ubicada en el interior del abrigo rocoso 1 (motivo 2).
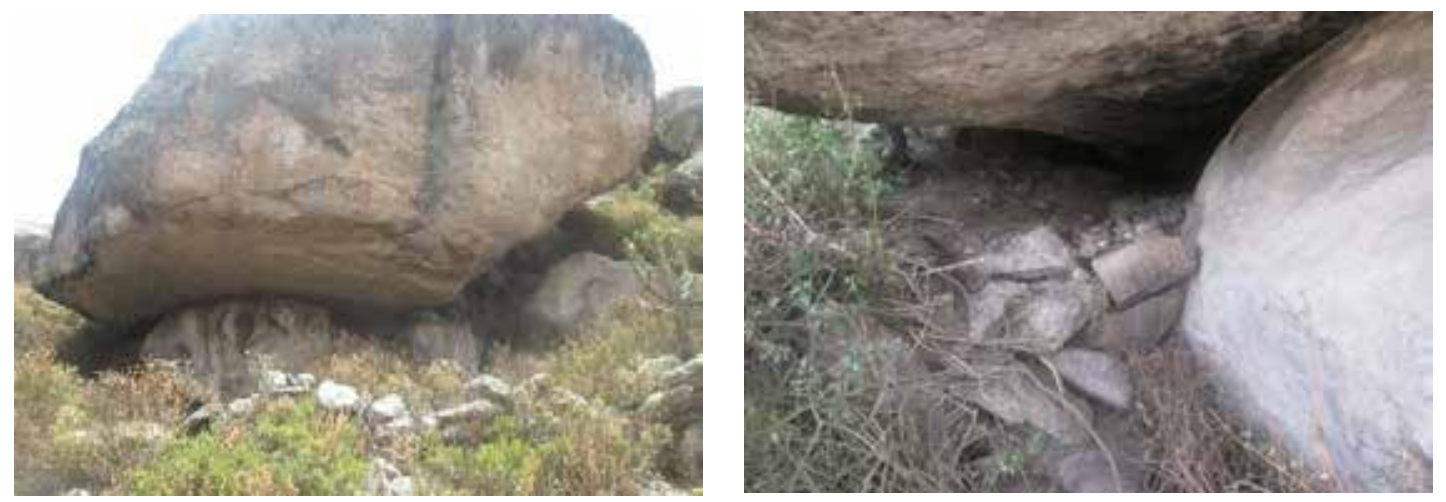

Figura 07 (izquierda). Vista panorámica del abrigo rocoso $N^{\circ}$ 2. Figura 8 (derecha): Vista de detalle del interior del abrigo rocoso $N^{\circ} 2$, donde se aprecia una patacha.
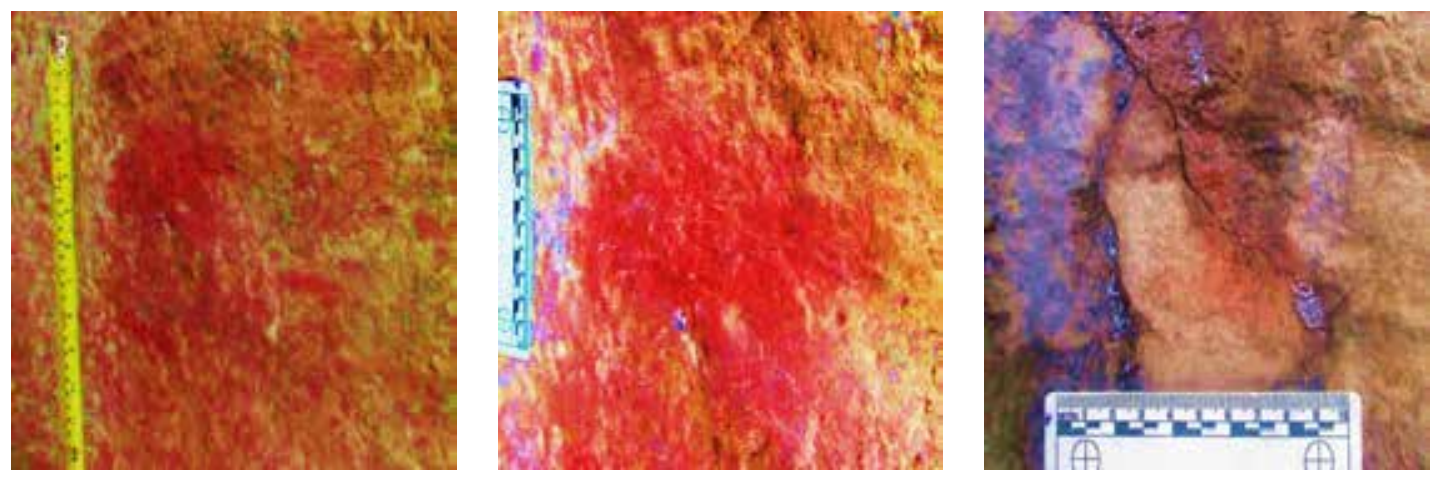

Figuras 09, 10 y 11. Vista de detalle de las pinturas rupestres ubicadas en el interior del abrigo rocoso $N^{\circ} 2$, correspondientes a manchas de color rojo por deterioro. 
turas rupestres de motivos circular y amorfos (mancha sin poder definir la forma). El motivo circular está conformado por un círculo de 9 centímetros de diámetro con líneas de 2 milímetros de grosor. La técnica del trazo es lineal (ver figura 12, 13 y 14).

Bosque de Piedra: Conformado por un yacimiento geológico de formaciones rocosas de diversos tamaños y formas. Así mismo, se encuentra rodeado por abrigos rocosos que presentan pintura rupestre y pequeñas estructuras funerarias tipo chullpa (ver figuras 15 y 16 ).

Asociación cronológica: Prehispánico. No hay evidencia diagnóstica, para determinar a un periodo cultural.

Estado de conservación: Regular. Los contextos funerarios identificados al interior de los abrigos rocosos se encuentran en su mayoría disturbados y hay abundante estiércol de ganado vacuno.

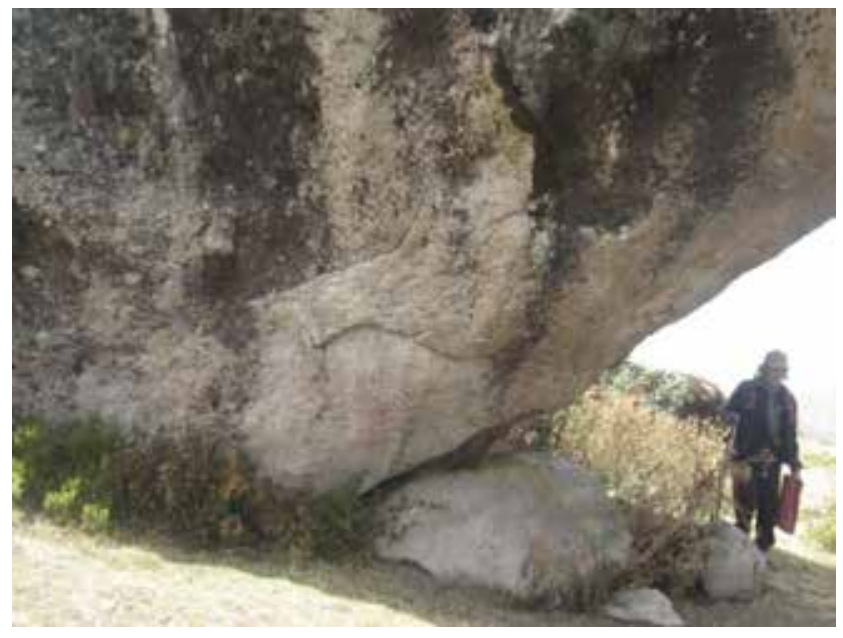

Figura 12. Vista Panorámica del Abrigo Rocoso $\mathrm{N}^{\circ}$ 3, foto tomada desde el lado norte.
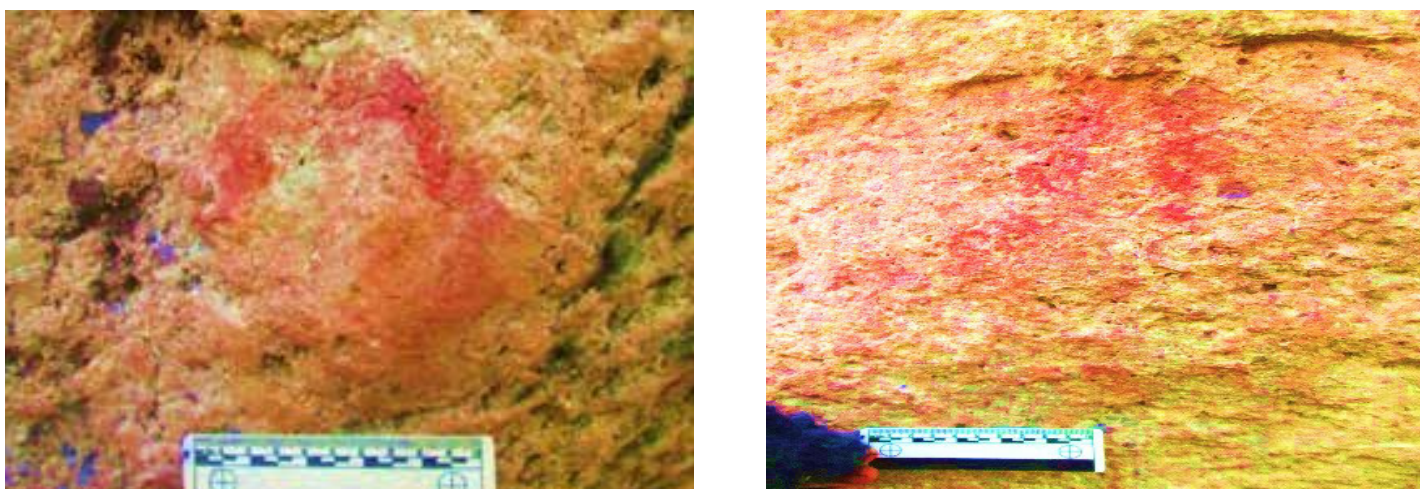

Figura 13 (izquierda). Vista de detalle del motivo circular de color rojo. Figura 14 (derecha): Vista de detalle de una pintura deteriorada correspondiente a una mancha de color rojo. 

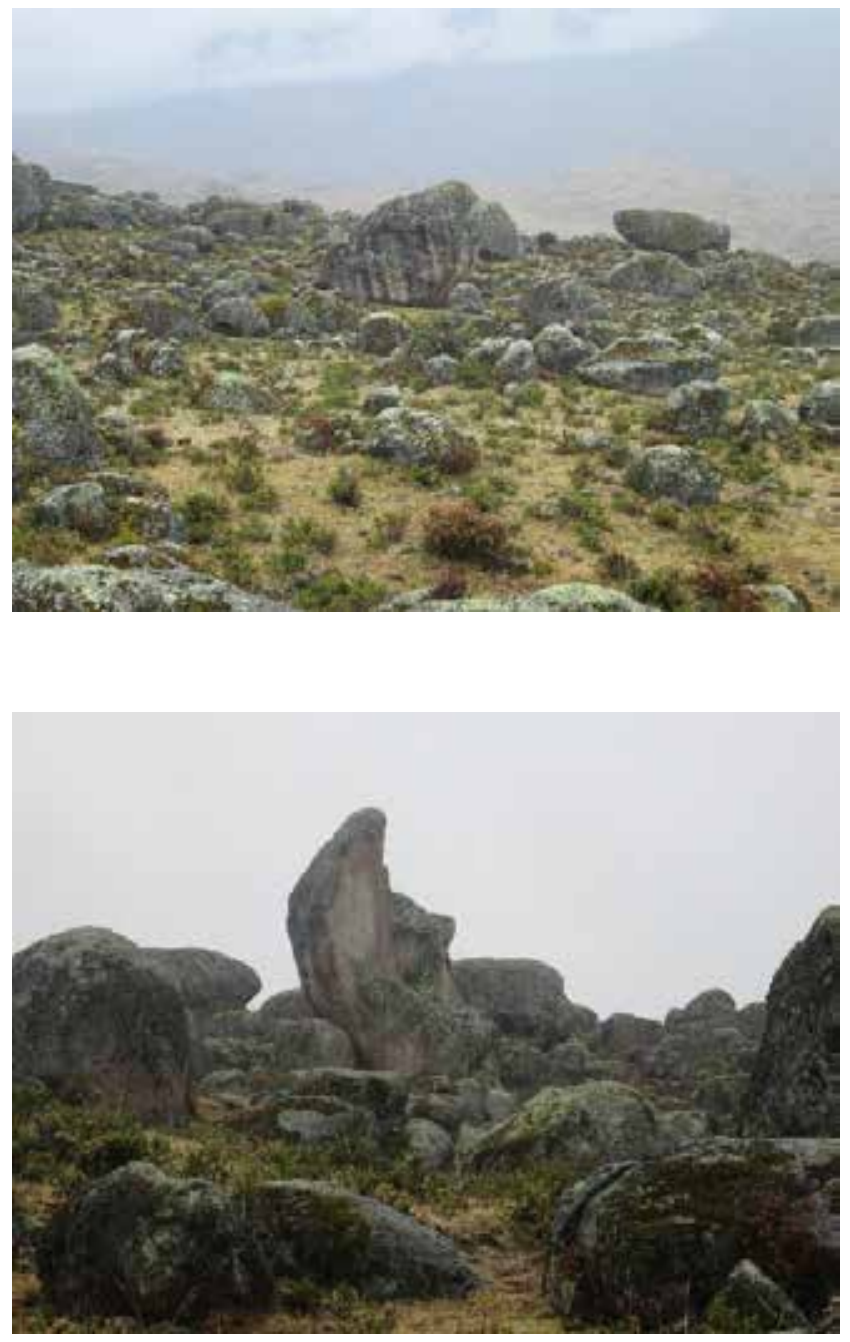

Figura 15 (izquierda). Vista Panorámica del sitio de Shansha conformado por un bosque de piedra.

Figura 16 (derecha). Vista de detalle de una roca que tiene la forma de una virgen.

\section{SITIO ARQUEOLÓGICO DE INTIRUMI}

Se encuentra localizado sobre la ladera de la quebrada del mismo nombre, en la margen derecha de la subcuenca del río Yarucaya. Geográficamente se ubica en las coordenadas UTM: 268311E, 8801307N, a una altitud de 3730 m s. n. m., en la jurisdicción de la Comunidad de San Juan de Yarucaya, distrito de Cochamarca, provincia de Oyón, región Lima. El acceso al sitio se realiza, desde el pueblo de San Juan de Yarucaya, siguiendo un camino de herradura con dirección al oeste, por un tramo de 1 hora y media de caminata. El nombre es un término quechua, "Inti" significa Sol y "rumi", piedra (piedra del Sol).

El sitio está conformado por un reservorio con su canal de drenaje, terrazas asociadas y un abrigo rocoso con evidencia pictórica. 
Reservorio: Se trata de un reservorio antiguo que se encuentra adosado a la ladera del cerro. Es de forma semicircular, de 15 metros de diámetro, con muros de contención a base de piedras medianas y grandes, mampuestas con la técnica del pircado simple de doble hilada, unido con mortero de barro, cuya altura máxima alcanza los 0.80 metros. La boca del reservorio se encuentra en el lado oeste, donde se puede observar canales simples de drenaje que se dirigen por la parte inferior de las terrazas (ver figuras 17, 18, 19 y 20).

Terrazas: Al oeste del sitio se encuentran estas terrazas, con una orientación de oeste a sureste y una longitud que varía, desde 12 metros hasta 15 metros de largo y una altura de 1 metro. La técnica constructiva es el pircado de doble hilada con piedras grandes en la parte baja del muro y las piedras medianas en la parte superior. Las terrazas están constituidas por muros de contención de variable altitud que alcanza de 0.80 a 1.00 metro. Las piedras utilizadas son canteadas de formas irregulares, obtenidas de canteras del mismo lugar. El ancho de las terrazas es variable, llegando a tener hasta 20 metros. Se ha identificado hasta 10 graderías continuas (ver figuras 21 y 22).

Abrigo rocoso con pintura rupestre: Se ubica al extremo sur del sitio, en las coordenadas UTM: 18L 268338E, 8801284N, cuya orientación es de este a oeste, con 2 metros de ancho por 1.30 metros de profundidad y una altura de 1.50 metros (ver figura 23). En la parte plana de la roca se aprecia dos paneles:

Panel 1 (ver figuras 24): Ubicado en el lado izquierdo del abrigo, presenta los siguientes motivos:

Motivo 1, conformado por un sol irradiado, estilizado, que presenta una combinación de dos colores: rojo y amarillo. Tiene una dimensión de $40 \mathrm{~cm}$ de diámetro y conformada por 16 líneas diagonales irradiadas (ver figura 25).

Motivo 2, corresponde a dos círculos concéntricos trazados en color rojo, con la parte intermedia de ambos círculos en color blanco. El círculo externo tiene $42 \mathrm{~cm}$
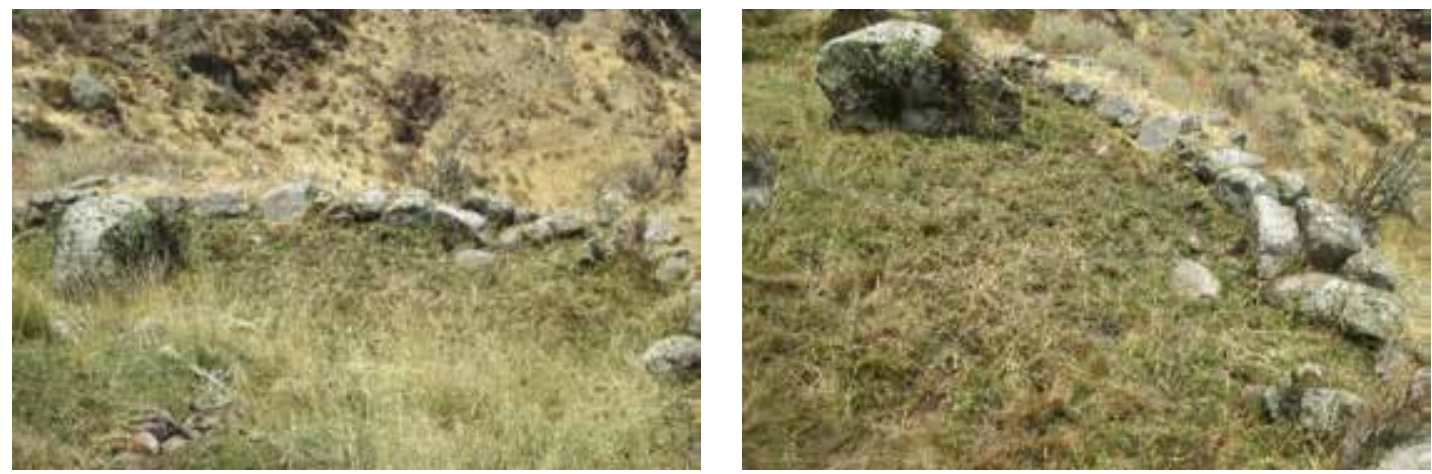

Figuras 17 y 18: Dos vistas del muro de contención de reservorio de Intirumi. 

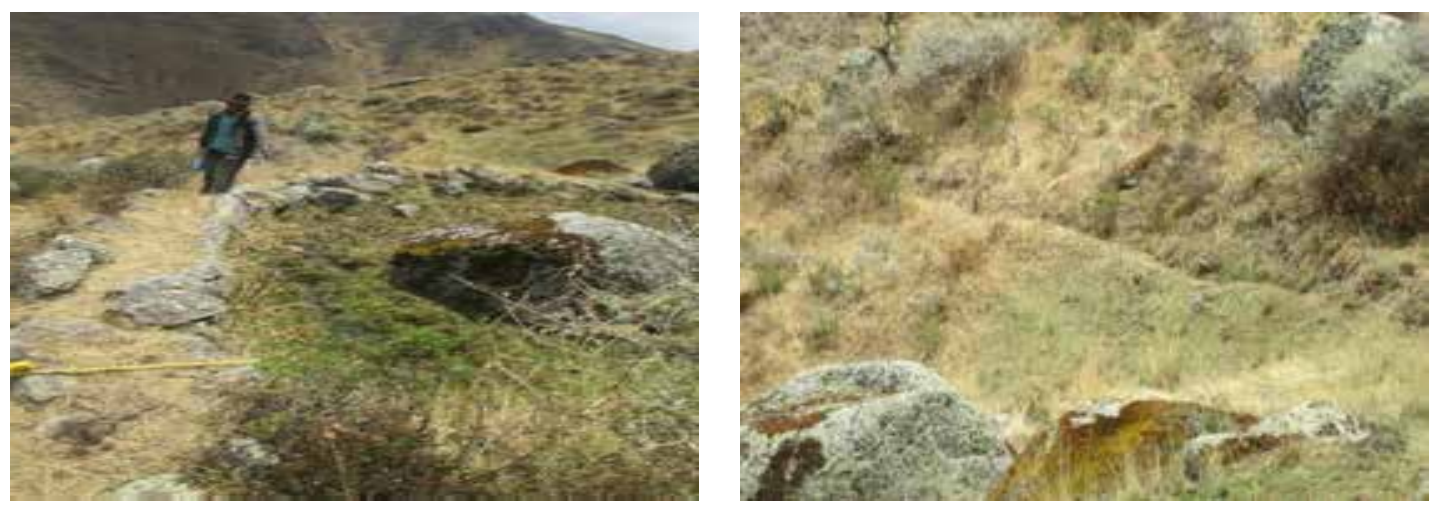

Figura 19 (izquierda). Vista de detalle del muro de forma semi circular del reservorio de Intirumi. Figura 20 (derecha). Vista de detalle de los canales que salen del reservorio hacia la parte inferior de las terrazas.
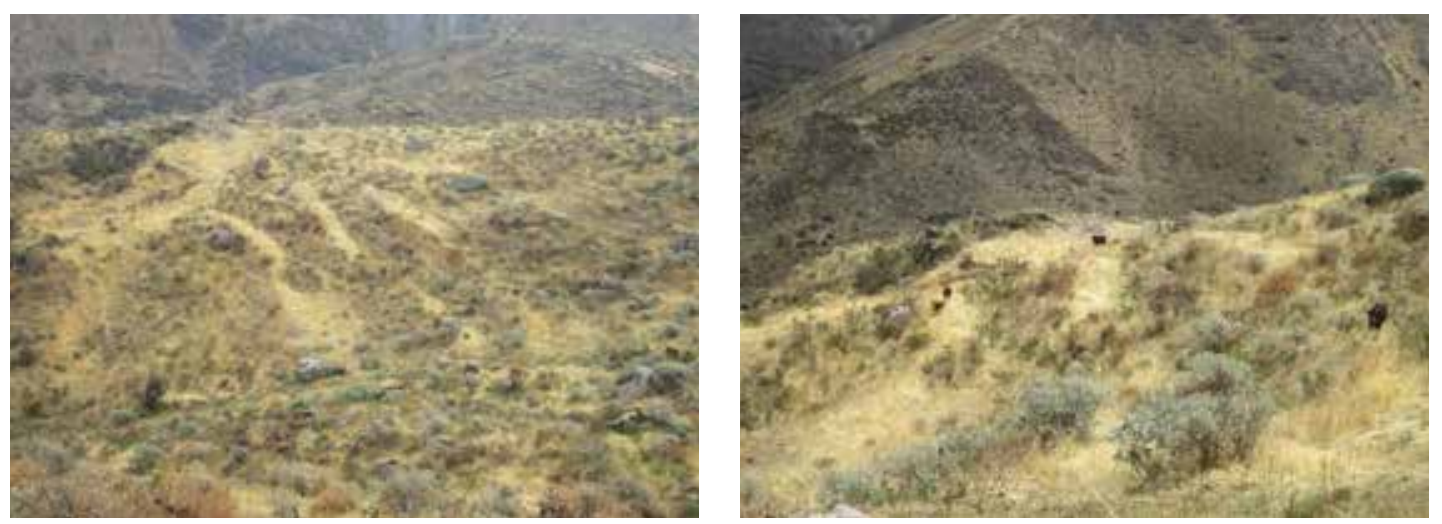

Figuras 21 y 22. Vista panorámica de las terrazas del sitio de Intirumi que se encuentra cubierta de vegetación.

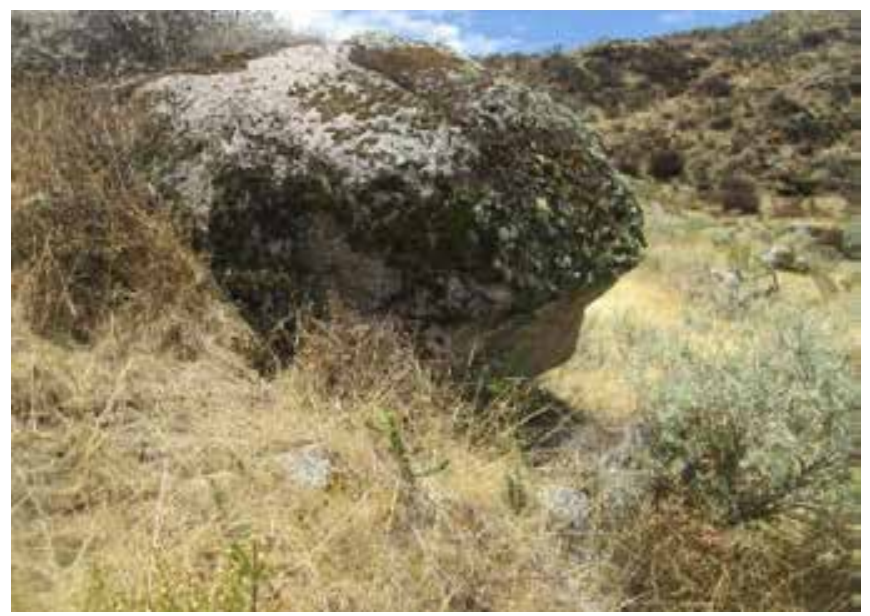

Figura 23. Vista panorámica del abrigo rocoso con evidencia pictográficas, foto tomada desde el lado oeste. 

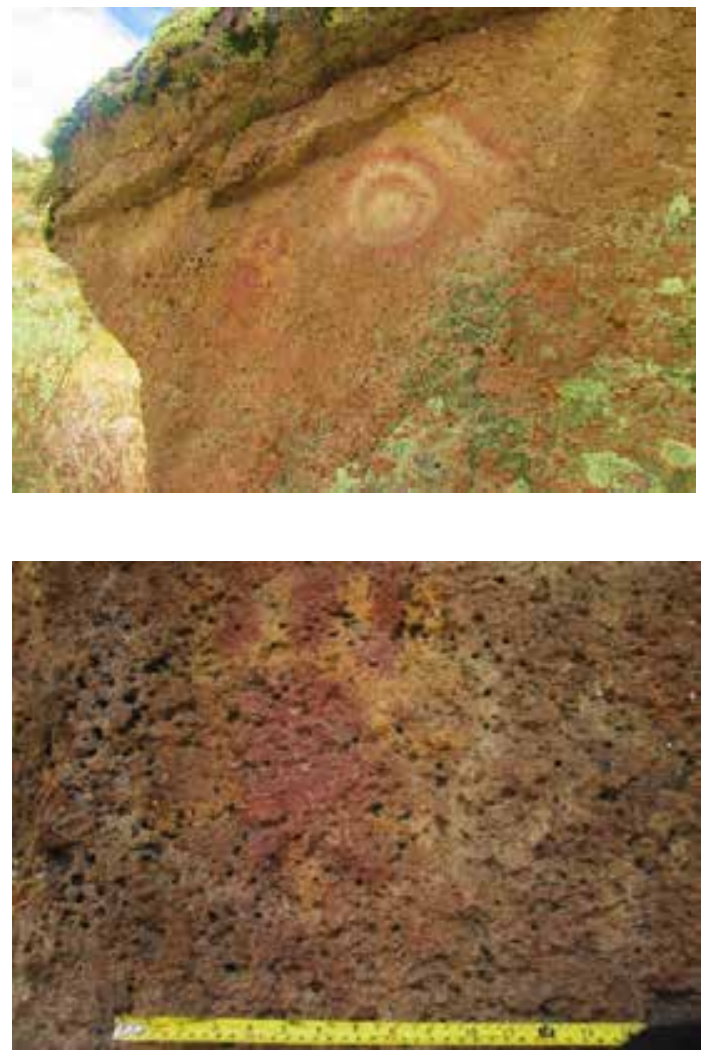

Figura 24. Vista en detalle del panel 1 correspondiente a las pinturas rupestres de Intirumi.

Figura 25 (izquierda). Vista de detalle del panel 1 correspondiente a un sol irradiado estilizado, elaborado con la combinación de dos colores rojo y amarillo. Figura 26 (derecha). Vista de detalle del motivo geométrico conformado por círculos concéntricos que varía de colores como blanco y rojo.

de diámetro. Al lado inferior de la figura se aprecia 3 líneas diagonales de tres colores: rojo, blanco y amarillo (ver figura 26).

Panel 2: Ubicado en la parte derecha de la roca, conformado por motivos zoomorfos (camélido) de color blanco y así mismo se aprecia un motivo compuesto por un círculo de color amarillo mostaza. Además, hay manchas de color blanco, que no se puede definir su silueta debido a la alteración que sufrió la pintura (ver figuras 27, 28, 29, 30 y 31).

Asociación cronológica: Precerámico.

Estado de conservación: Regular. Las terrazas y reservorio presentan una alteración, como caída de los muros por parte de animales (como vacunos) que transitan por la zona actualmente.

\section{SITIO ARQUEOLÓGICO DE PINTIMACHAY}

El Sitio se encuentra emplazado en una ladera conformada por afloraciones rocosas, en la margen izquierda de la sub cuenca del río Yarucaya. Políticamente se ubica 
en la Comunidad de San Juan de Yarucaya, distrito de Cochamarca, provincia de Oyón, región Lima. El acceso es mediante un camino de herradura, tomando la ruta desde el poblado de San Juan de Yarucaya, con dirección hacia el este, pasando por el sitio de Ciclacancha posteriormente desviándose por un camino para arribar a la ladera, hasta llegar al sitio. La zona se encuentra conformada por 3 abrigos rocosos con pinturas rupestres. A continuación, se detalla cada uno de ellos:

Abrigo rocoso $\mathrm{N}^{\circ}$ 01: Se ubica al lado superior de las afloraciones rocosas, en las coordenadas UTM: 273536E, 8800331N, a una altitud de 4076 m s. n. m. Se encuentra orientado de norte a sur. Presenta forma semicircular, de 6 metros de ancho, 4.30 metros de profundidad y una altura de 5 metros. En el interior de dicho abrigo se encuentra basamentos de viviendas de planta rectangular que se encuentran cubiertos de abundante vegetación; así mismo, en el extremo sur del abrigo se aprecia un muro de contención a manera de plataforma, edificada para poder nivelar y sobre ella construir las viviendas. En la parte este del abrigo presenta un acceso oculto, ascendiendo mediante escalinatas al interior del abrigo. En el interior se puede apreciar restos óseos de animal vacuno contemporáneo y abundante vegetación arbustiva espinosa (figuras 32 y 33 ).

Abrigo rocoso $\mathrm{N}^{\circ}$ 02: Se ubica en la parte inferior a escasos metros del abrigo rocoso $\mathrm{N}^{\circ} 1$, en las coordenadas UTM: 273515E, 8800334N, a una altitud de $4075 \mathrm{~m}$ s. n. m. Se encuentra orientado de norte a sureste, presenta 12 metros de ancho, 3 metros de profundidad y una altura aproximada de 5 metros. En el interior se aprecia abundante estiércol de animal vacuno. En las paredes planas de la roca, hacia el extremo oeste, se puede apreciar la existencia de pintura rupestre de motivos antropomorfos, amorfos y geométricos (ver figuras 34 a 40).

Motivo antropomorfo: Está compuesto por un personaje que se encuentra de pie con las piernas abiertas, los brazos los tiene uno hacia abajo y el otro levantado; asimismo presenta cabellos irradiados. La técnica de elaboración es en trazo lineal, color rojo oscuro, de $40 \mathrm{~cm}$ de altura.

Motivo amorfo: Ubicado a $10 \mathrm{~cm}$ de la figura antropomorfa, corresponde a una figura amorfa, al parecer tiene la forma de un corazón, diseño elaborado de color rojo oscuro y técnica trazo lineal.

Motivos geométricos: En la parte superior de los motivos ya mencionados, se puede apreciar figuras geométricas que se encuentran dispersas en dicho panel. Se identificó figuras como: círculo, líneas verticales, puntos rellenados de color rojo. La técnica de elaboración es el trazo lineal, color rojo oscuro.

Abrigo rocoso $\mathrm{N}^{\circ}$ 03: Se localiza a unos 20 metros al lado sur del abrigo $\mathrm{N}^{\circ} 02$, en las coordenadas UTM $273532 \mathrm{E}, 8800306 \mathrm{~N}$, a una altitud de $4075 \mathrm{~m} \mathrm{~s}$. n. m., presenta una forma ovalada, ligeramente inclinada, de 6 metros de ancho, 3 metros de profundidad y una altura de 5 metros. En las paredes de la roca se encuentra una gran diver- 


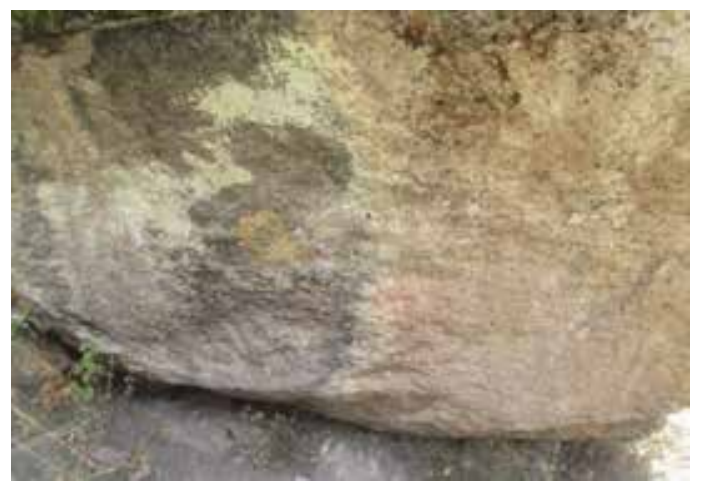

Figura 27. Vista Panorámica del Panel 2 del sitio de Intirumi.
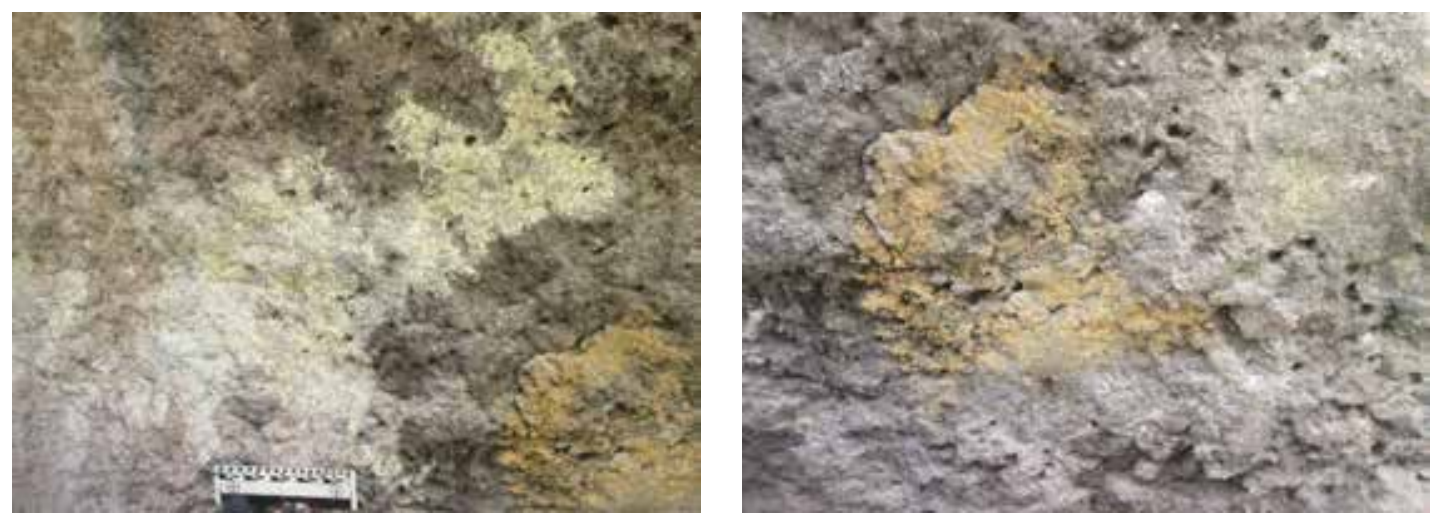

Figura 28 (izquierda). Vista de detalle de motivo zoomorfo (camélido) elaborado de color blanco. Figura 29 (derecha). Vista de detalle de un motivo circular elaborado en color amarillo.
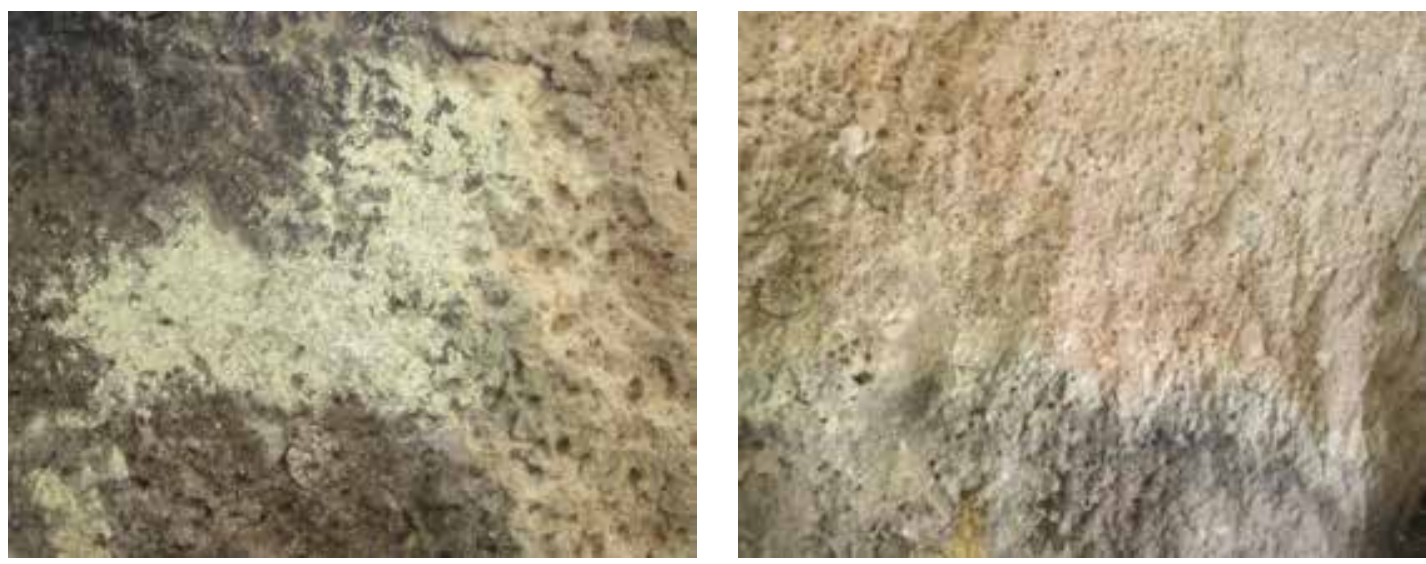

Figura 30 (izquierda). Vista en detalle de un motivo amorfo, mancha color blanco. Figura 31 (derecha). Vista de mancha color rojo. 

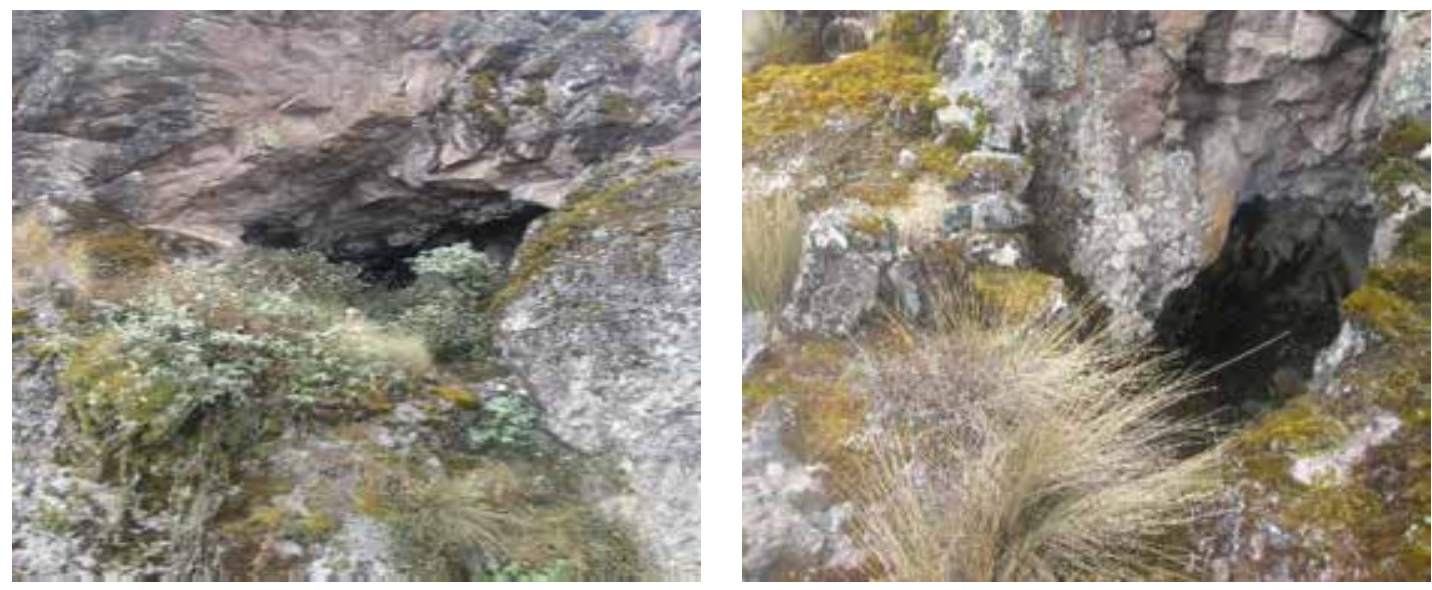

Figura 32 (izquierda). Vista panorámica del abrigo rocoso $N^{\circ} 1$ del sitio Pintimachay, foto tomada desde el lado Sur. Figura 33 (derecha). Vista de detalle del acceso de dicho abrigo que se encuentra cubierta de vegetación ichu.
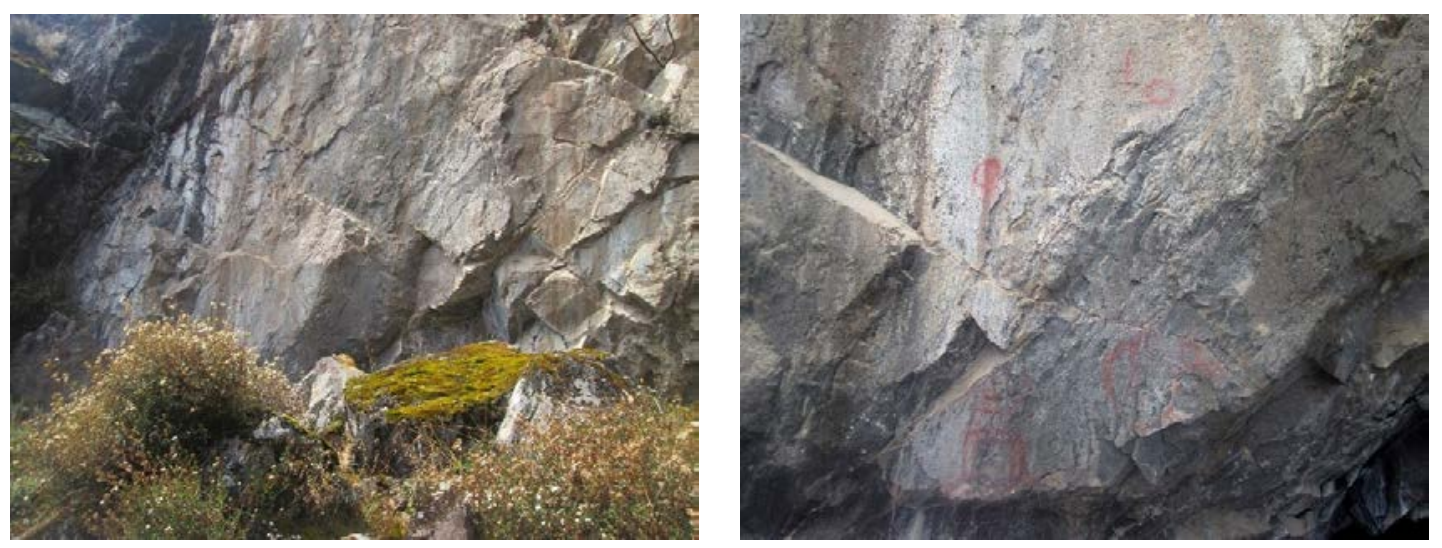

Figura 34 (izquierda). Vista panorámica del abrigo rocoso $N^{\circ} 2$ de Pintimachay, foto tomada desde el lado sur. Figura 35 (derecha). Vista en detalle de la pared del abrigo rocoso donde se puede apreciar manifestaciones pictóricas elaboradas con pintura de color rojo.
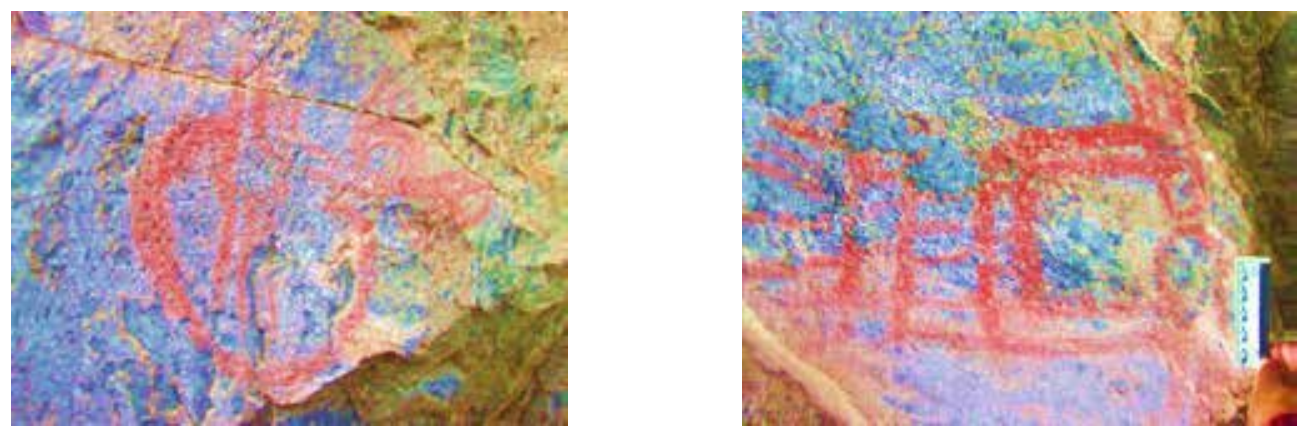

Figura 36 (izquierda). Vista de detalle de la pintura con motivo antropomorfo del abrigo rocoso $N^{\circ} 2$. Figura 37 (derecha). Vista de motivo amorfo (no identificable en forma de un corazón) elaboradas con pintura de color rojo. 

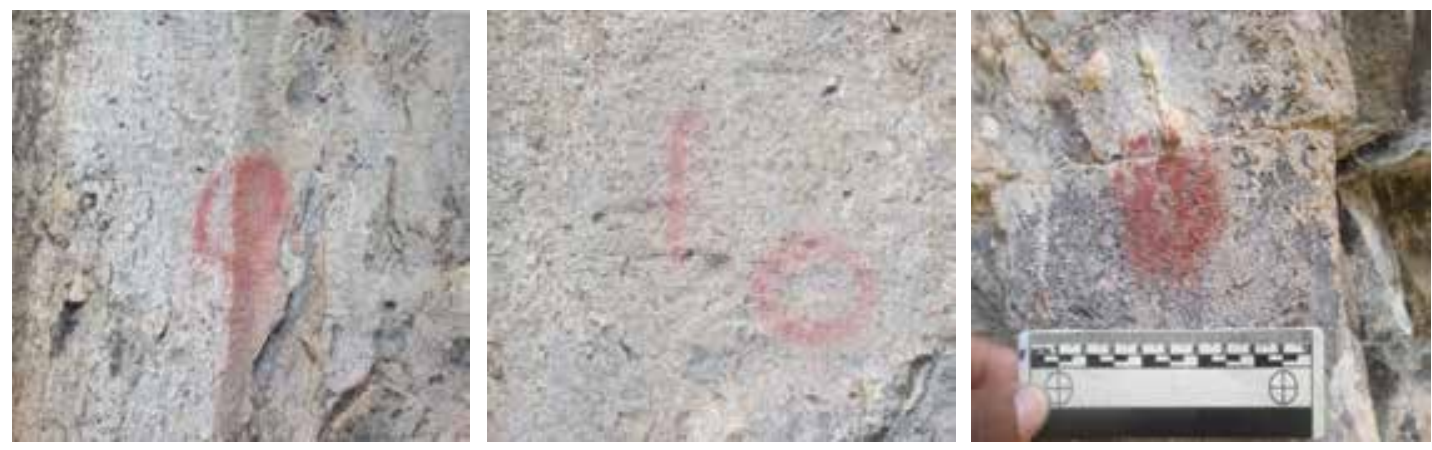

Figura 38 (izquierda). Vista de detalle de motivo de círculo espiral. Figura 39 (centro): Vista en detalle de una línea vertical y un círculo elaborados en color rojo. Figura 40 (derecha). Vista en detalle de un círculo con relleno rojo.

sidad de pinturas rupestres, conformado por motivos geométricos, círculos, líneas verticales, espirales, círculos concéntricos, sol irradiado, etc. Así mismo, se observan motivos antropomorfos y motivos zoomorfos, como: camélidos, aves, serpientes, lagartijas y otras especies sin identificar. También se puede apreciar escenas de trampas de camélido en el cual se puede apreciar a un hombre que está arrimando a un camélido hacia las trampas, que son pequeños espacios hechos bajo tierra. Hay también paneles con escenas de camélidos con sus respectivas crías (ver figuras del 41 al 62).

Los tres abrigos rocosos fueron ocupados durante el periodo Precerámico, asociados con cazadores de camélidos, con reocupación posterior en la que se edificó un recinto en el abrigo 1 . Todo el sitio se encuentra en regular estado de conservación, en su mayoría cubierta con vegetación herbácea y arbustiva. Por otro lado, hay evidencia de alteración antrópica con la remoción de los contextos arqueológicos. Las pinturas rupestres presentan alteración por factores climáticos.

\section{INTERPRETACIONES SOBRE LAS QUILCAS DE YARUCAYA}

Las quilcas que hemos identificado en la localidad de San Juan de Yarucaya se encuentran ubicados a altitudes entre los 3750 y 4100 metros de altitud, es decir en terrenos de la región Suni, región natural ubicada entre los 3500 y 4100 metros de altura (Pulgar, 1996), ubicado en alturas con respecto al fondo del valle del río Yarucaya, casi en la divisoria de aguas con otras sub cuencas vecinas o en las laderas altas de la cuenca.

Las evidencias rupestres que hemos identificado en esta comunidad nos hacen referencia a una larga tradición rupestre que se inicia desde periodos tempranos, pudiendo clasificarse en las siguientes fases:

1. Fase 1: Corresponde al Precerámico Temprano, con representaciones de figuras naturalistas, conformados por círculos simples, círculos concéntricos y círculos irradiados. Hay escenas de camélidos simples y camélidos que son perseguidos por personas para ser llevados a trampas. Las figuras son elaboradas en color rojo. 
2. Fase 2: Correspondería al Precerámico Tardío, con la complejización de estas mismas representaciones, pero con el uso de otros colores además del rojo; por ejemplo, los camélidos pintados de color amarillo cremoso. A esta fase también corresponde el sol irradiado en rojo de Pintimachay, en la cual se han raspado las partes de la roca que no han sido pintados; así como otras figuras de Intirumi.

3. Fase 3: Correspondería a periodos prehispánicos tardíos, son figuras más complejas, estilizadas y abstractas. La figura de la cabeza con el cabello estilizado hacia arriba de Pintimachay también corresponde a esta fase.

Muchas de las figuras y motivos que hemos identificado en Yarucaya las hemos encontrado en otras provincias cercanas, como en la provincia de Bolognesi, donde en la cuenca alta del río Fortaleza hemos identificado sitios arqueológicos con quilcas en Cajacay (van Dalen, Huashuayo y Huamaní, 2016) donde en Pinturamachay se halló representaciones similares de círculos concéntricos o espirales, al igual que en la localidad de Yamor (van Dalen, Obregón y Allende; 2015, van Dalen, Allende y Obregón; 2019); al igual que en la cuenca alta del río Pativilca o Aynín, donde se halló una significativa dispersión de sitios con quilcas de similares características (van Dalen, Obregón, Carhuas, Huamaní, palomino; 2019). En la vecina cuenca alta del río Chancay, se han reportado sitios similares como Araro en Santa Cruz de Andamarca (van Dalen y Huashuayo, 2019), con numerosas representaciones de camélidos seguidos por cazadores y en la vecina región de Pasco en las pinturas de Huayllay (Maita, 2004; UNDAC, 1996).

En el ámbito de la actual provincia de Oyón no existen estudios sobre sitios con arte rupestre, salvo el reporte que hace Arturo Ruiz (2014) del sitio Mayhuajoyo en el pueblo de Naván, cuyos motivos guardan similitud con los que hemos presentado en Yarucaya, formando parte de la misma tradición.

La función ceremonial que cumplían los sitios se mantuvo hasta periodos prehispánicos tardíos, por ello, se han adosado edificaciones en algunos de los abrigos rocosos que sirven de soporte a las quilcas, como estructuras funerarias tipo chulpas, depositando en su interior a miembros de la sociedad y nación andax, buscando su descanso eterno en áreas de gran significación religiosa y sagrada.

Los motivos representados en estos tres sitios arqueológicos (Shansha, Pintimachay e Intirumi), están referidos a los elementos naturales del medio donde se desarrollaron; siendo los elementos astrales y naturales sacralizados desde periodos arqueológicos tempranos, manteniendo este status hasta la invasión española, siendo en el Tawantinsuyu el dios sol o Inti la máxima divinidad pan-andina. Las representaciones del sol, se han dado a través del tiempo Precerámico y Horizonte Temprano, desde los más simple hacia lo más complejo, involucionando ligeramente en su representación tras la caída de la influencia Chavín (Echevarría, 2015). 


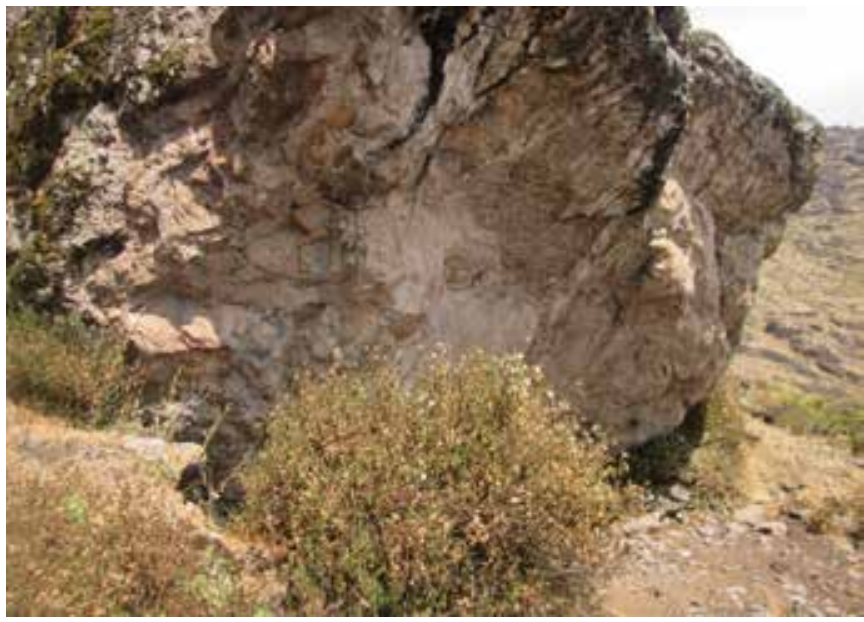

Figura 41. Vista panorámica del abrigo rocoso $N^{\circ} 3$ del sitio de Pintimachay.
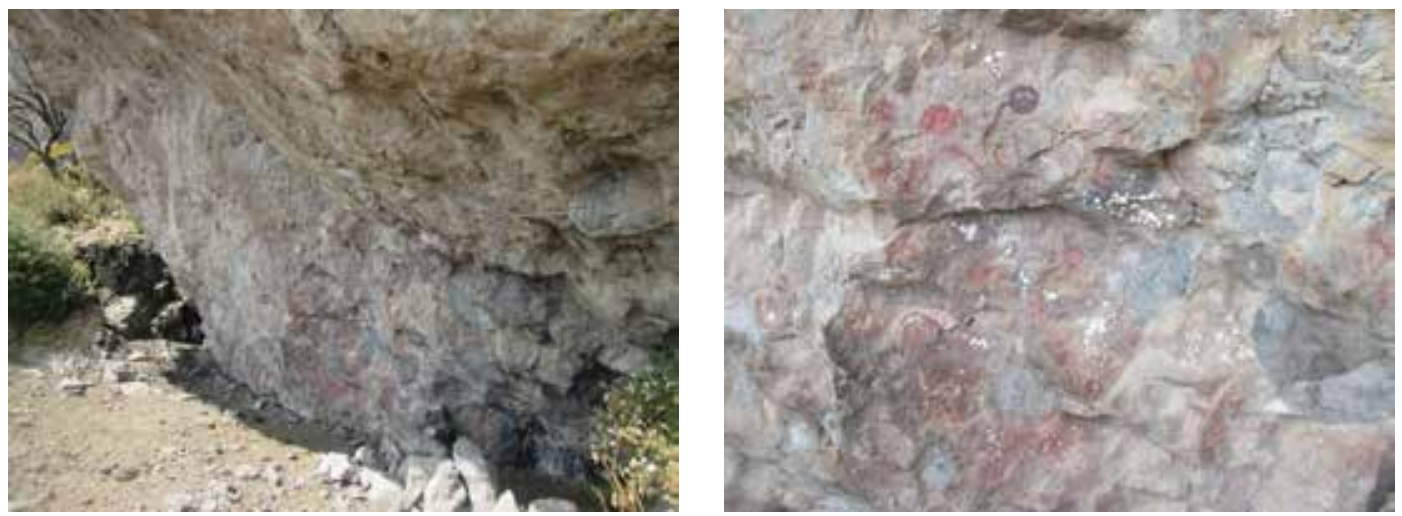

Figuras 42 y 43. Vista de detalle del interior del abrigo rocoso $N^{\circ} 3$, nótese las quilcas en color rojo.
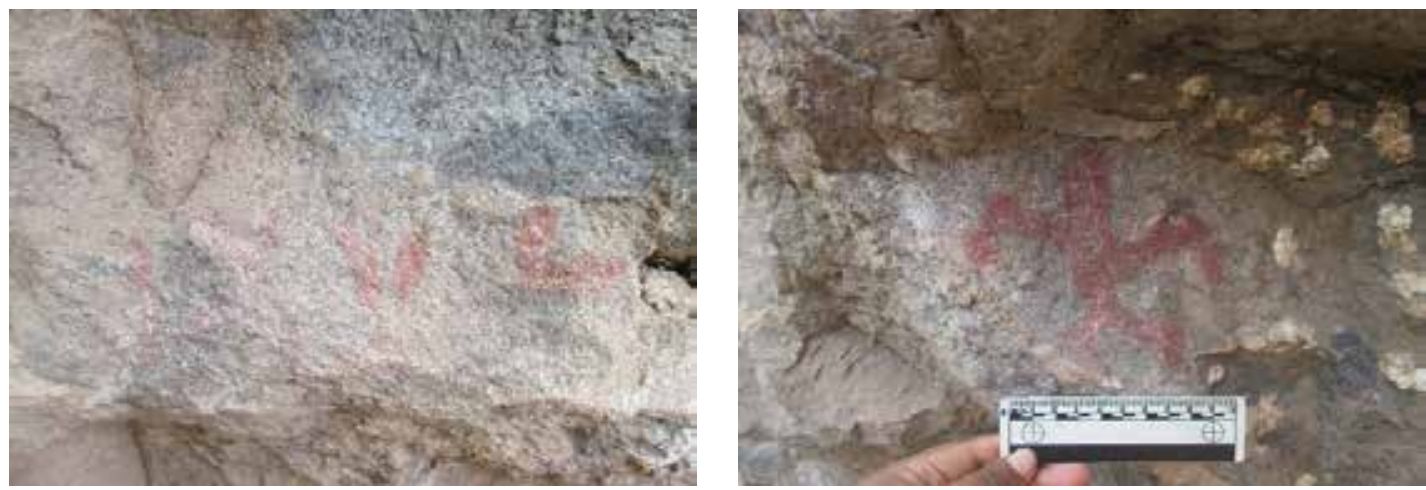

Figuras 44 y 45. Vista en detalle de motivos geométrico y zoomorfo elaboradas en color rojo oscuro. 

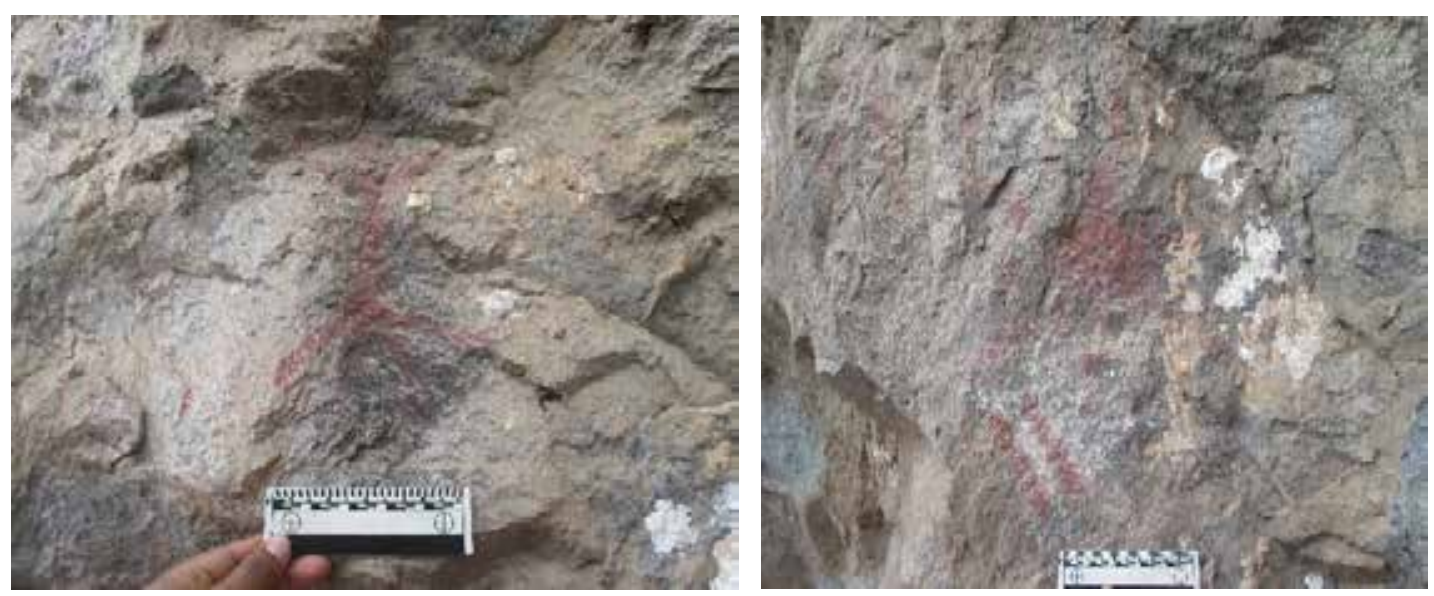

Figuras 46 y 47. Vista en detalle de motivos antropomorfo y estilizado.
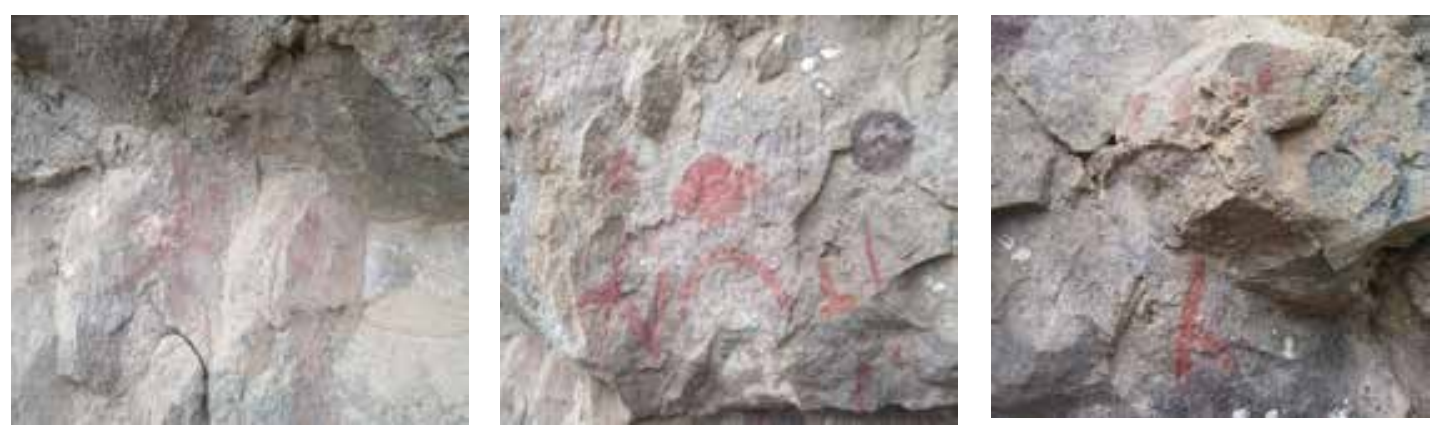

Figuras 48, 49 y 50. Vista de detalle de motivos geométrico, zoomorfos y manchas elaborada de color rojo.
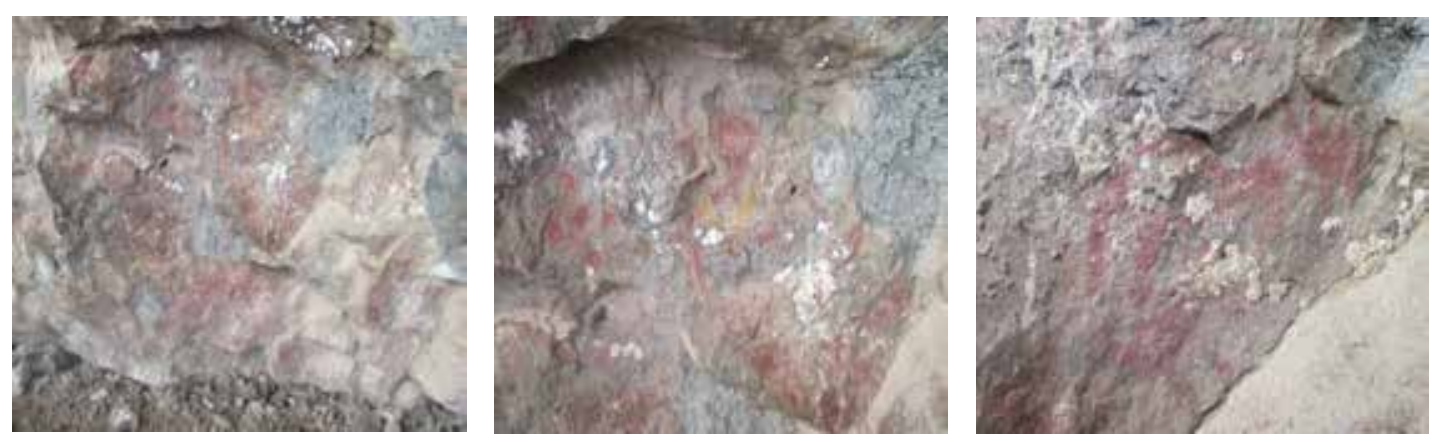

Figuras 51, 52 y 53. Vista en detalle de figuras antropomorfas, geométricas y zoomorfas (camélidos). 

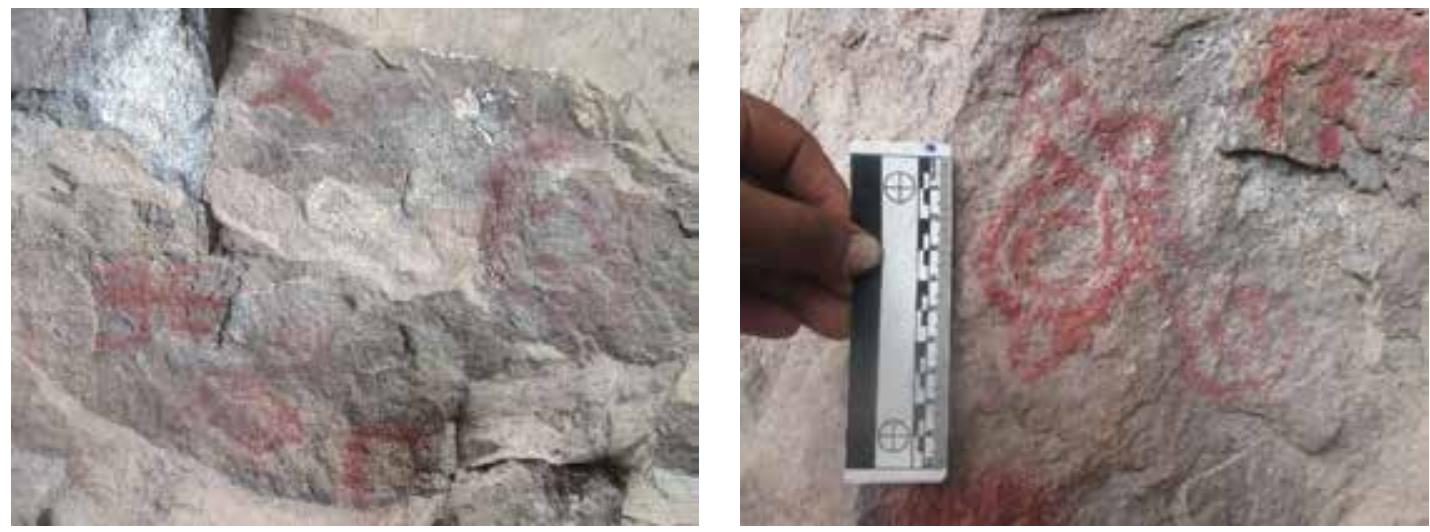

Figuras 54, 55. Vista en detalle de motivos zoomorfos conformado por aves, serpientes, etc.
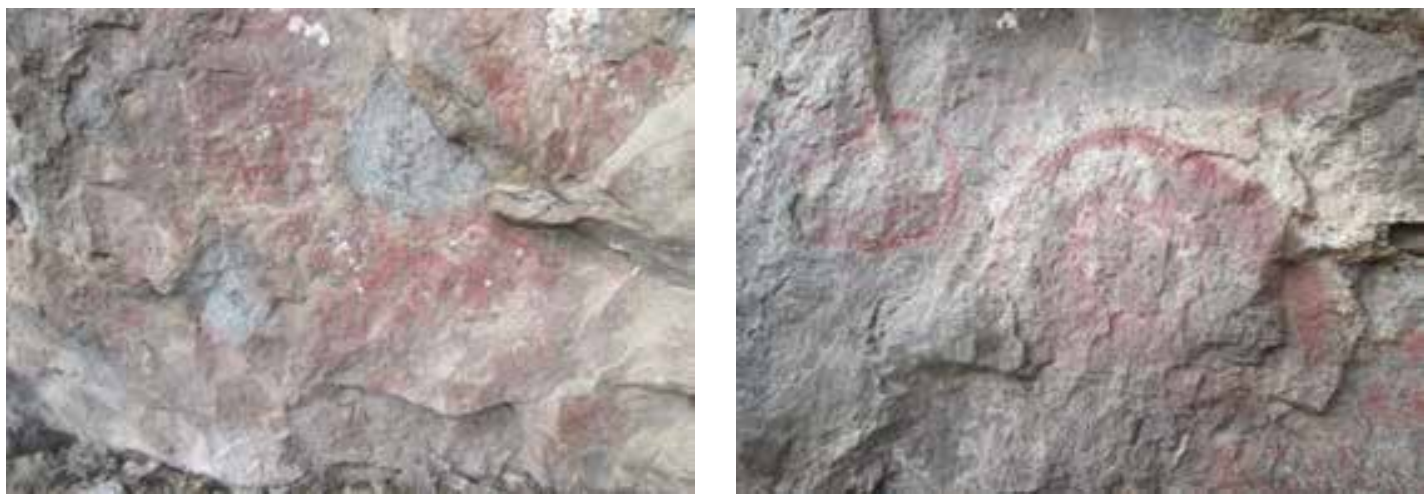

Figura 56 (izquierda). Vista en detalle de motivos antropomorfo y zoomorfo (camélidos). Figura 57 (derecha). Vista en detalle de círculos y manchas de color rojo y blanco.
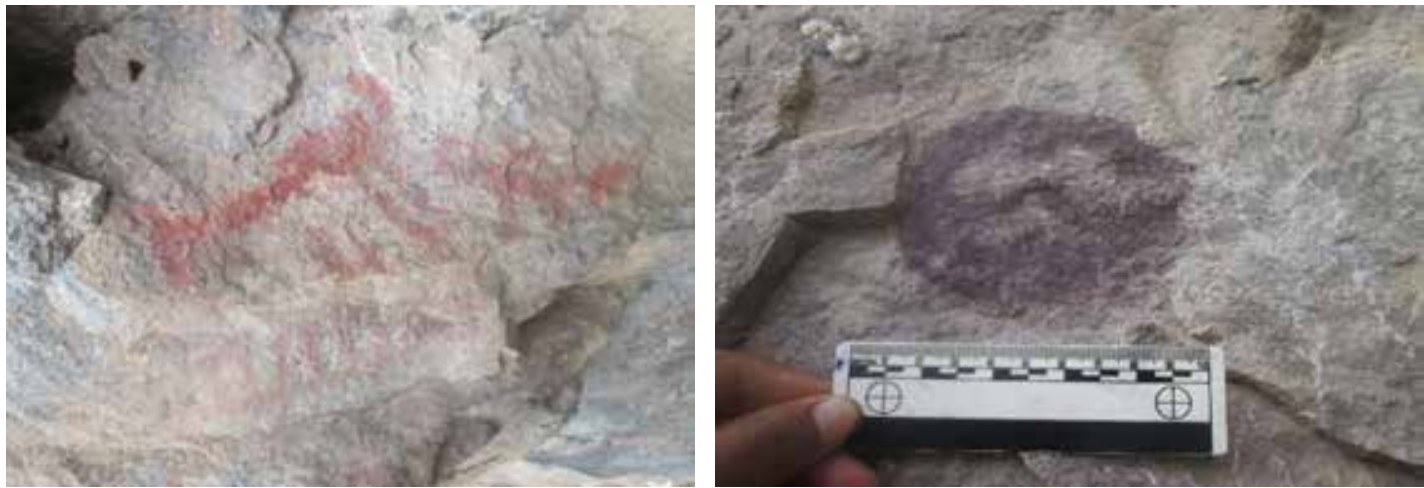

Figura 58 (izquierda). Vista en detalle de la escena de un camélido y un personaje antropomorfo que lo está arrimando hacia las trampas. Figura 59 (derecha): Vista en detalle de un círculo de color guinda con relleno interno. 

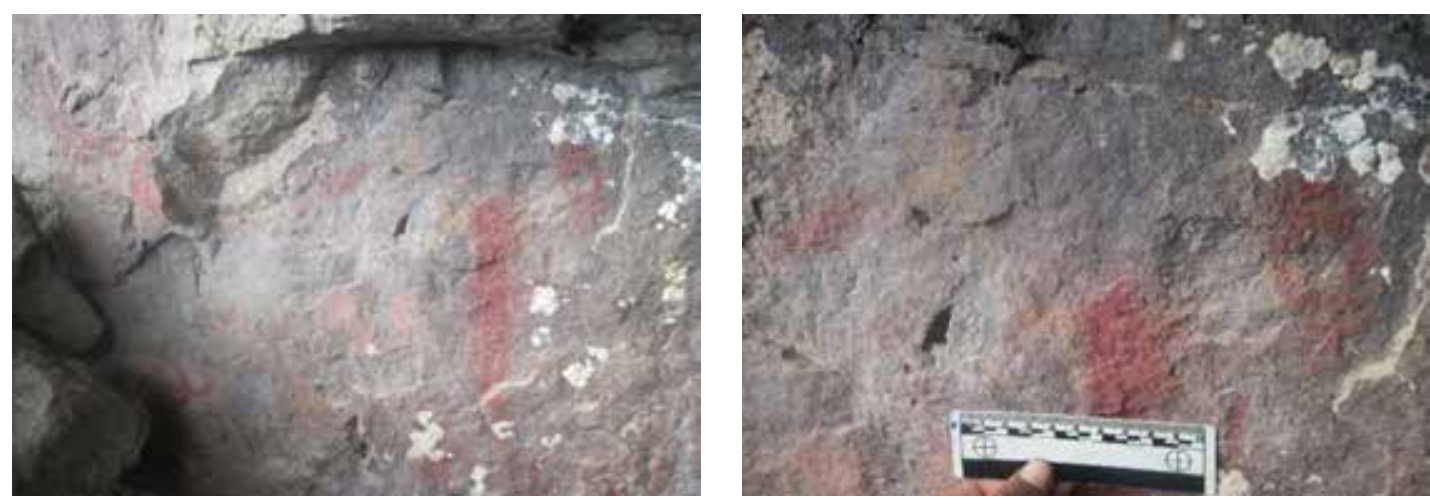

Figura 60 (izquierda). Vista en detalle de figuras zoomorfas como aves y camélidos que se encuentran dispersos, elaborados en color rojo y naranja. Figura 61 (derecha). Vista en detalle de un camélido de color naranja y sobre ella una mancha roja superpuesta, muy próximo a la figura de otro círculo de color rojo.

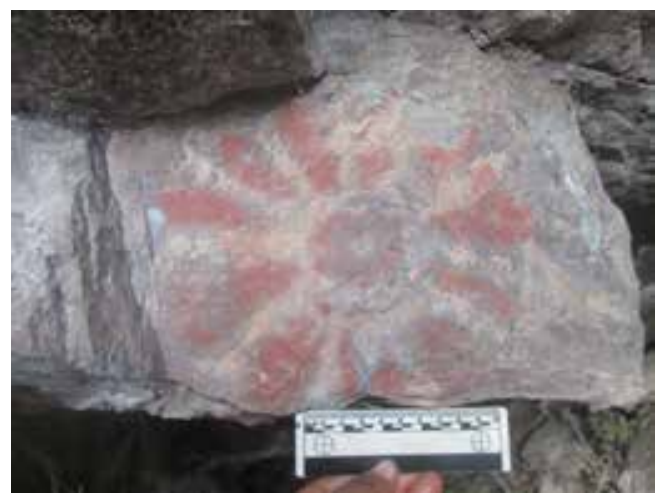

Figura 62. Vista en detalle de la figura de un sol estilizado e irradiado que presenta dos colores el rojo y el naranja oscuro.

De igual manera, desde periodos tempranos, la fauna - en especial los camélidosfueron la dispensa alimenticia de los pobladores del Ande, no solo aprovisionando carne para su alimentación, sino brindando la materia prima para protegerse del intenso frío que hace en estas regiones altoandinas. Por ello, la caza de camélidos, primero, y luego su crianza, fueron episodios muy importantes y ritualizados en la sociedad andina, motivo por el que se plasmaron en muchas latitudes del Ande, como se ve en Toquepala de Tacna (Ravines, 2016), en la provincia de Yauyos en sitios como Yuncalara de Laraos (van Dalen, 2012); en el valle de Ayacucho o del Pampas (Pérez, 2015), en Huánuco (Domínguez, 2018), entre otras regiones. Para el sitio de Pintimachay, en la figura 52 se puede apreciar la imagen de un camélido preñado (hembra) con sus cuatro patas, mientras que en la figura 58 también se observa a un camélido con sus cuatro patas.

Los colores utilizados en las representaciones rupestres de la cuenca del río Yarucaya son principalmente el rojo (en un $80 \%$ ), con sus variaciones en tonalidades 
a ocre y rojo claro (esto según la naturaleza del pigmento y a la exposición a los agentes naturales); además, se utilizan el amarillo, naranja y blanco. El amarillo se presenta en motivos individuales, mientras que el naranja y blanco se utiliza interactuando en motivos en que también se utiliza el color rojo. Los pigmentos utilizados para el trazo de las figuras rupestres habrían sido obtenidos de canteras locales, el rojo se obtenía del óxido de hierro, el amarillo de mezcla de flores con otros mordientes, mientras que el blanco se obtuvo de los depósitos de cal, siendo el naranja el resultado de la mezcla de dos o mas de estos colores.

\section{CONCLUSIONES}

El arte rupestre o quilcas identificadas en los sitios arqueológicos de Shansha, Pintimachay e Intirumi, forman parte de una larga y continua tradición rupestre, que presenta por lo menos 3 fases, siendo la más antigua del Precerámico Temprano, la segunda del Precerámico Tardío y la última de periodos prehispánicos tardíos. Esta es la primera evidencia del arte rupestre del distrito de Cochamarca y la provincia de Oyón, existiendo en la cuenca alta del río Huaura, más de un centenar de sitios arqueológicos similares aún por descubrir e investigar. Futuros estudios del arte rupestre de esta provincia permitirán conocer más detalles sobre esta extensa tradición cultural prehispánica, que abarcó, además, a otras provincias vecinas.

Agradecimientos: Nuestro mayor agradecimiento y reconocimiento a las personas que han hecho posible la investigación en la Comunidad campesina de San Juan de Yarucaya, a la arqueóloga Yesenia Huashuayo Casavilca, a los estudiantes de arqueología Miguel Mota, Vivian Condori y Víctor Medina Torres. Las investigaciones arqueológicas en el distrito de Cochamarca han sido posibles gracias a la iniciativa y gestiones de Nilder Castillo León. Un agradecimiento especial al alcalde distrital de Cochamarca Don Fernando Carrera Gervasio, por el apoyo en la presente investigación. A la directiva de la Comunidad Campesina de San Juan de Yarucaya, a todos los comuneros y a sus autoridades políticas.

\section{REFERENCIAS BIBLIOGRÁFICAS}

Dominguez Condeso, V. (2018). Quillqa. Mensajes de Piedras y Montañas. Escritura en los Andes Centrales del Perú. Huánuco, 240 pp.

Echevarría López, T. (2015). Secuencia y cronología de las quilcas o arte rupestre de Lima. Tesis para optar el título profesional de licenciado en Arqueología, E.P. de Arqueología, Facultad de Ciencias Sociales, Universidad Nacional Mayor de San Marcos. Lima.

Maita Agurto, P. (2004). Pictografías de Camélidos en el Santuario Nacional de Huayllay, 


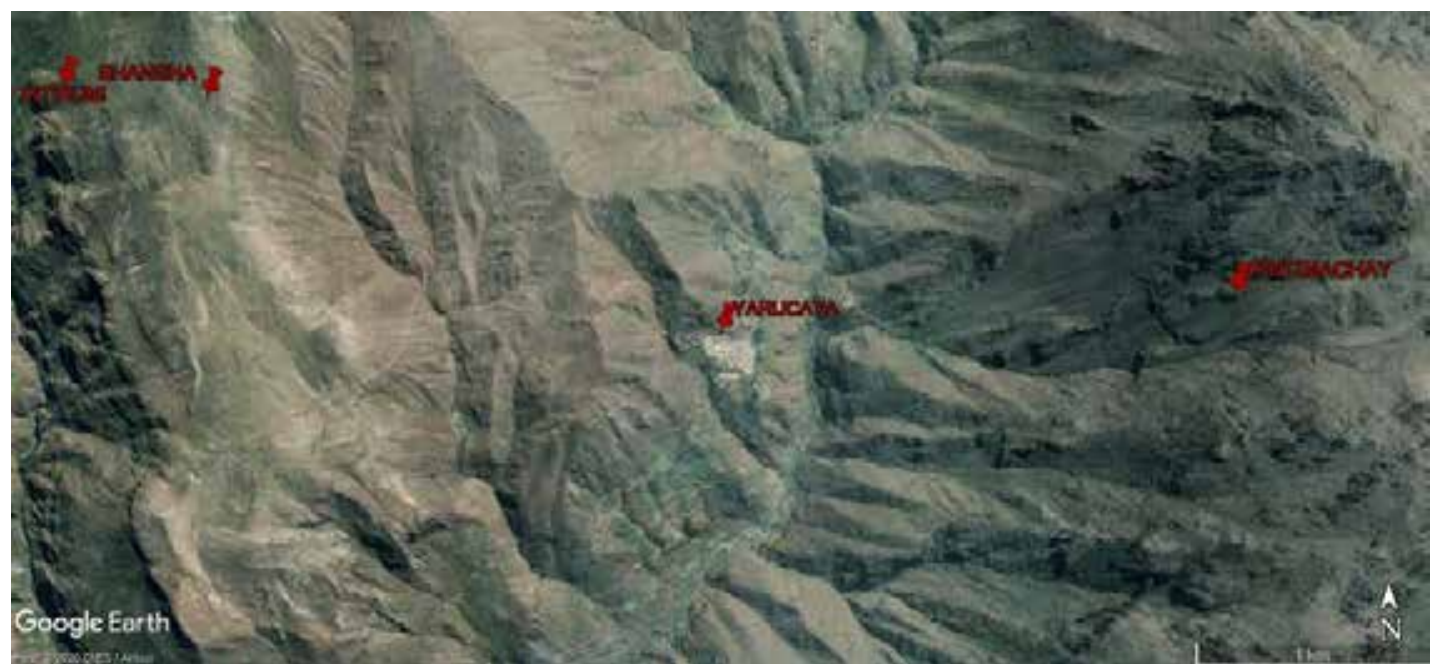

Figura 63. Ubicación de los tres sitios arqueológicos con quilcas y del pueblo de Yarucaya. Fuente: Google Earth.

Pérez Calderón, I. (2015). Paisaje, pinturas y formas de vida doméstica en las punas de la cuenca del Pampas, Ayacucho. Actas de ponencias del V Simposio Nacional de Arte Rupestre. Universidad Nacional Mayor de San Marcos. Lima, pp. 89-106.

Pulgar Vidal, J. (1996). Geografía del Perú. Las Ocho Regiones Naturales. Décima edición. Lima.

Ravines, R. (2016). Toquepala Arqueología. Boletín de Lima, 182. Ed. Los Pinos. Lima, pp. 1-356.

Ruiz Estrada, A. (2014). Notas sobre el arte rupestre de Naván. Guara. Revista del Museo de Arqueología de la Universidad Nacional José Faustino Sánchez Carrión, 18. Huacho, pp. 7-11.

van Dalen Luna, P. (2012). Arte rupestre en la cuenca alta del río Cañete, provincia de Yauyos. Actas y ponencias del IV Simposio Nacional de Arte Rupestre Federico Kauffmann Doig. Universidad Nacional San Cristóbal de Huamanga. Ayacucho, pp. 69-96.

van Dalen Luna, P., Allende Joaquín, D. y Obregón Pillaca, H. (2019). Arqueología de Raquia y Yamor, Distrito de Antonio Raymondi, provincia de bolognesi, departamento de Ancash: Cuenca alta del Río Fortaleza. Nuevos datos para la comprensión de la arqueología del sur de Ancash. Ed. Gutemberg. Lima, 168 pp.

van Dalen Luna, P. y Huashuayo Casavilca, Y. (2019). Las quilcas o pinturas rupestres de Araro, Santa Cruz de Andamarca, Huaral. En Pieter van Dalen (Ed.). Recientes investigaciones sobre sitios con quilcas o arte rupestre en el Perú (pp. 69-78). 
van Dalen Luna, P., Huashuayo Casavilca, Y. y Huamaní Perlacios, J. (2016). “El hallazgo de nueve sitios arqueológicos con quillcas en Cajacay, Bolognesi-Ancash". Arqueología y Sociedad, 31. Museo de Arqueología y Antropología, Universidad Nacional Mayor de San Marcos. Lima, pp. 471-494.

van Dalen Luna, P., Obregón Pillaca, H., Allende Joaquín, D. (2015). El arte rupestre de Yamor, cuenca alta del río Fortaleza, Bolognesi-Ancash. Arqueología y Sociedad, 29, pp. 407-461. Museo de Arqueología y Antropología, Universidad Nacional Mayor de San Marcos. Lima.

van Dalen Luna, P., Obregón Pillaca, H., Carhuas Tenorio, H., Huamaní Perlacios, J., y Palomino Gutiérrez, J. L. (2019). Quilcas en la cuenca alta del Río Aynín (Pativilca), provincia de Bolognesi - Ancash. En Pieter van Dalen (Ed.). Recientes investigaciones sobre sitios con quilcas o arte rupestre en el Perú (pp. 26-46).

\section{SOBRE EL AUTOR}

\section{Pieter Dennis van Dalen Luna}

Licenciado en Arqueología (UNMSM), Bachiller en Ciencias de la Educación (UNEEGV-LC), Magíster en Arqueología Andina (UNMSM), Magíster en Gestión del Patrimonio Cultural (UNMSM), Estudios Doctorado Ciencias Sociales con mención en antropología (UNMSM) y Doctorado en el Programa de Estudios Andinos Arqueología especialidad en arqueología (PUCP). Diplomado en Conservación especializado en arquitectura arqueológica. Docente nombrado de la UNMSM, departamento académico de arqueología. Premio al Mérito Científico UNMSM 2012. Exdirector del Museo de Arqueología y Antropología de San Marcos-UNMSM (2012-2017). Exvicedecano nacional del Colegio de Arqueólogos (2018-2019). Director del proyecto de Investigación Arqueológica Chancay-Huaral-Atavillos (PACHA). 